\title{
アルキルベンゾイルアクリル酸誘導体の 合成とその抗菌性
}

\author{
阿 部 芳 郎・小山 内 州一・奥村恵一郎 \\ 慶応義塾大学工学部（横浜市港北区日吉 3-14-1)

\begin{abstract}
Synthesis and Antimicrobial Properties of Alkylbenzoylacrylic Acid Derivatives
\end{abstract} \\ Yoshirō ABe, Shūichi OsanaI, and Keiichirō Okumura \\ Faculty of Engineering, Keio University (3-14-1, Hiyoshi, Kōhoku-ku, Yokohama)
}

\begin{abstract}
Water soluble alkali metal salts of butyl, octyl and dodecylbenzoylacrylic acids were derived from the corresponding less soluble alkylbenzoylacrylic acids. And the antimicrobial activity and surface tension of their aqueous solutions were examined. They show the antimicrobial activity significantly against Gram positive bacilli, but lesser extent against Gram negative bacilli and fungi. For the anti= microbial activity, octylbenzoyl acrylate is superior and for the surface activity, 3-(2-hydroxy-3octylbenzoyl)acrylate is superior.

Then the effect of the introduction of hydroxyl or acetylamino group to the alkylbenzoyl acrylic acid on the antimicrobial power and surface activity were also compared.
\end{abstract}

\section{1 緒 言}

芳香核に長鎖基をもつ 3-(4-アルキルベンゾイル) ア クリル酸は Kirchner らにより初めて合成され，あわ せてそれらの抗菌性が測定されたが，ノニルベンゾイル アクリル酸が最もすぐれた抗菌力を示し，ノニル基より アルキル基が大きくても, 小さくても抗菌力が低下し, またその界面活性はノニル基, デシル基をもつものを除 いて明白に表れない。

この場合, アルキル基の大きい遊離の酸では水溶性が 極めて小さいと考えられるのでそれらを可溶性塩に変え た場合, 表面張力及び抗菌力に与える影響について検討 した。塩としてはナトリウム塩 (一部カリウム塩) 及び トリエタノールアミン塩を用いた。

つぎにベンゼン核にヒドロキシル基及びアセチルアミ ノ基を導入し置換基の種類, 位置の差が抗菌性や界面活 性に与える影響について検討した。フェノール性ヒドロ キシル基やアセチルアミノ基の抗菌性に与える影響はよ 〈知られており ${ }^{1), 2)}$ ベンゾイルアクリル酸について特に フェノール性ヒドロキシル基導入の影響がくわしく研究 されているがそれらの結果は既報間ではなはだしく相反 している。

\section{2 実験および結果}

$2 \cdot 1$ 3-(4-アルキルベンゾイル) アクリル酸のナトリ ウム塩及ひトリエタノールアミン塩

アルキルベンゾイルアクリル酸は Kirchner らの報告 ${ }^{12}$

に準じ Scheme-1 の反応式にしたがって合成した。得 られた 3-(4-アルキルベンゾイル) アクリル酸（1）の 定数注次のとおりである。 $\mathrm{R}=\mathrm{C}_{3} \mathrm{H}_{7^{-}}, \mathrm{mp} 91 \sim 92^{\circ} \mathrm{C}(90$ $\left.\sim 91^{\circ} \mathrm{C}^{1)}\right), \mathrm{NV} 241.5(241.8) ; \mathrm{R}=\mathrm{C}_{7} \mathrm{H}_{15^{-}}, \mathrm{mp} 77 \sim 78$ ${ }^{\circ} \mathrm{C}\left(77 \sim 78^{\circ} \mathrm{C}^{1)}\right), \mathrm{NV} 194.4(194.5) ; \mathrm{R}=\mathrm{C}_{11} \mathrm{H}_{23^{-}}, \mathrm{mp}$ $82 \sim 84^{\circ} \mathrm{C}\left(81 \sim 82^{\circ} \mathrm{C}^{1)}\right), \mathrm{NV} 166.9(162.8)$.（）㹥 献值または計算值, 以下同様とする。

ナトリウム塩はそれぞれの遊離酸をエタノールに溶解 し, 計算量の $1 / 10 \mathrm{~N}$ 水酸化ナトリウムエタノール溶液 を充分にかくはんしながら加え, 溶媒を留去し残分を真 空乾燥後エーテルにてよく洗浄したもの試料とした。 またトリエタノールアミン塩は遊離酸と等モルのトリエ タノールアミンをアセトン中で $30 \mathrm{~min}$, 室温でかくはん 後, 溶液を泠却して析出する結晶をアセトンから再結晶 し試料とした。定数は次のようである。 $\mathrm{R}=\mathrm{C}_{3} \mathrm{H}_{7}^{--}, \mathrm{mp}$ $\left({ }^{\circ} \mathrm{C}\right) 79 \sim 80, \mathrm{~N}(\%): 3.38(3.64), \mathrm{R}=\mathrm{C}_{7} \mathrm{H}_{15^{-}}, \mathrm{mp} 61$ $\sim 63, \mathrm{~N}: 3.07$ (3.17), $\mathrm{R}=\mathrm{C}_{11} \mathrm{H}_{23}{ }^{-}, \quad \mathrm{mp} 66 \sim 68, \mathrm{~N}:$ 2.27 (2.81)。 


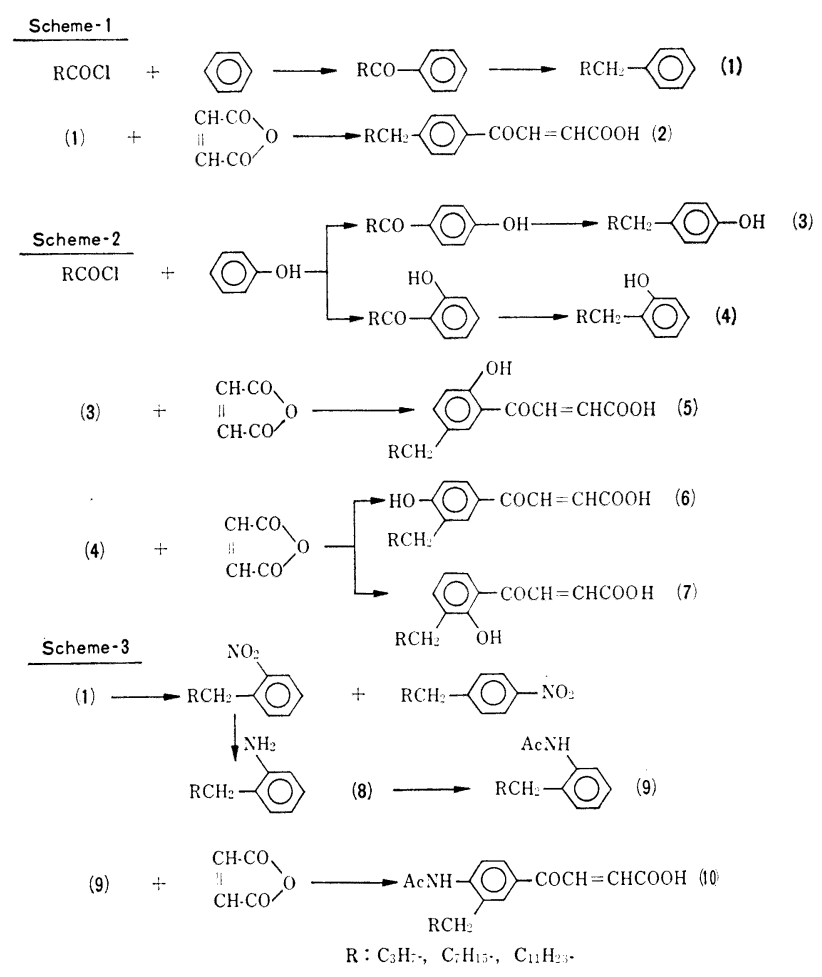

Fig.-1 Preparation of benzoylacrylic acids derivatives.
$2 \cdot 2 \cdot 2$ ヒドロキシアルキルベンゾイルア クリル酸 $(5),(6),(7)$

ヒドロキシオクチルベンゾイルアクリル酸 の合成例について次に述べる。反応は古賀の 3-(3-メチル-4-ヒドロキシベンゾイル) アク リル酸合成法 ${ }^{6)}$ を参照した。無水マレイン酸 $9.8 \mathrm{~g}(0.1 \mathrm{~mol})$, 無水塩化アルミニウム $27 \mathrm{~g}$ $(0.2 \mathrm{~mol})$ 及びテトラクロロエタン $30 \mathrm{ml}$ を かくはん棒, 滴下漏斗を備えた三つロフラス コにとり氷冷しながら o-オクチルフェノー ル $20.6 \mathrm{~g}(0.1 \mathrm{~mol})$ のテトラクロロエタン $(20 \mathrm{ml})$ 溶液を $30 \mathrm{~min}$ で滴下し, 滴下終 了後室温にて 5〜 $6 \mathrm{~h}$ かくはんする。一夜放置 後, 内容を冷却して水 $50 \mathrm{ml}$, さらに濃塩酸 $25 \mathrm{ml}$ を徐々に加え，ついで咸圧下にテトラクロロエタ ン及び水を留去した。残分をエーテルに溶解し， 水洗, 硫酸ナトリウム (無水物) で乾燥後エーテ ルを留去した。残分にベンゼン:アセトン $=5: 1$ の混合溶媒 $60 \mathrm{ml}$ を加え得られた淡黄色固体を 同一溶媒で融点が一定になるまで再結晶を繰り返 し 3-(4-ヒドロキシー3-オクチルベンゾイル) ア クリル酸 $2.7 \mathrm{~g}$ （収率 $9 \%$ ）を淡黄色結晶として 得た。また前の再結晶の母液より溶媒を留去した 後, 残分をへキサン:ベンゼン $=2: 1$ の混合溶 媒で再結晶を繰り返すことにより 3-(2-ヒドロキシ-3オクチルベンゾイル)アクリル酸 $0.9 \mathrm{~g}$ (収率3\%) を橙 色結晶として得た。なお p-オクチルフェノールの場合 は 3-(2-ヒドロキシ-5-オクチルベンゾイル) アクリル 酸のみが黄色結晶として収率 19\%で得られた。再結晶 溶媒はへキサン：アセトン=10：1 の混合溶媒を使用し た。他のアルキル基の同族体についても同様に合成し た。それらの定数を Table-2 に示す。ベンゼン核に導 入された置換基の位置は NMR によって確認した。ア

Table-2 Characteristics of 3-(hydroxyalkylbenzoyl) acrylic acids (5), (6), (7).

\begin{tabular}{|c|c|c|c|c|}
\hline & Alkyl & $\begin{array}{l}\text { Position } \\
\text { of } R\end{array}$ & $\mathrm{mp}\left({ }^{\circ} \mathrm{C}\right)$ (Ref.) & $n_{\mathrm{D}}^{25 \cdot 5}(\text { Ref. })^{3)}$ \\
\hline 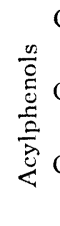 & $\begin{array}{l}\mathrm{C}_{8} \mathrm{H}_{7} \\
\mathrm{C}_{7} \mathrm{H}_{15^{-}} \\
\mathrm{C}_{11} \mathrm{H}_{23^{-}}\end{array}$ & $\begin{array}{l}o- \\
p- \\
o^{-} \\
p^{-} \\
o^{-} \\
p^{-}\end{array}$ & $\begin{array}{l}91 \sim 92(91 \sim 91.5)^{3)} \\
\overline{(62.5)^{3)}} \\
61 \sim 62(42.5 \sim 43.5)^{4)} \\
44 \sim 45(42) \\
71 \sim 72(70 \sim 71)^{4)}\end{array}$ & $\begin{array}{c}1.5370(1.5375) \\
- \\
- \\
-\end{array}$ \\
\hline 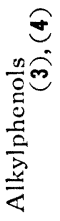 & $\begin{array}{l}\mathrm{C}_{3} \mathrm{H}_{7}- \\
\mathrm{C}_{7} \mathrm{H}_{15}- \\
\mathrm{C}_{11} \mathrm{H}_{28}-\end{array}$ & $\begin{array}{l}o- \\
p- \\
o- \\
p- \\
o- \\
p-\end{array}$ & $\begin{array}{c}\overline{-} \\
\overline{(41 \sim 42)^{3)}} \\
40 \sim 41(4) \\
41 \sim 42^{(* *)} \\
63 \sim 64(64.5 \sim 65.5)^{5)}\end{array}$ & $\begin{array}{c}1.5179(1.5180) \\
1.5160(1.5165) \\
1.5022(1.5029) \\
1.4938^{(*)}(1.4938) \\
-\end{array}$ \\
\hline
\end{tabular}

\begin{tabular}{c|c|c|c|c|c|c}
\multicolumn{7}{|c}{ acrylic acids (5),(6), (7). } \\
\hline Alkyl & & $\mathrm{mp}{ }^{\circ} \mathrm{C}$ & $\mathrm{C} \%$ & $\mathrm{H} \%$ & $\mathrm{NV}$ & Yield \% \\
\hline \multirow{3}{*}{$\mathrm{C}_{3} \mathrm{H}_{7^{-}}$} & $(\mathbf{5})$ & $131 \sim 133$ & 67.52 & 6.56 & 225.3 & 29 \\
& $(\mathbf{6})$ & $190 \sim 192$ & 67.44 & 6.53 & 224.1 & 13 \\
& $(\mathbf{7})$ & $127 \sim 129$ & 67.49 & 6.54 & 226.7 & $<5$ \\
& & & $(67.72)$ & $(6.49)$ & $(226.0)$ & \\
\hline \multirow{3}{*}{$\mathrm{C}_{7} \mathrm{H}_{15^{-}}$} & $(\mathbf{5})$ & $118 \sim 119$ & 71.02 & 8.04 & 183.3 & 19 \\
& $(\mathbf{6})$ & $152 \sim 153$ & 71.17 & 7.95 & 183.8 & 9 \\
& $(\mathbf{7})$ & $109 \sim 112$ & 70.77 & 7.97 & 183.6 & $<5$ \\
& & & $(71.02)$ & $(7.94)$ & $(184.3)$ & \\
\hline \multirow{3}{*}{$\mathrm{C}_{11} \mathrm{H}_{28}$} & $(\mathbf{5})$ & $116 \sim 117$ & 73.64 & 9.04 & 153.1 & 16 \\
& $(\mathbf{6})$ & $133 \sim 134$ & 72.99 & 8.82 & 151.9 & 6 \\
& $(7)$ & $106 \sim 107$ & 73.04 & 8.81 & 155.9 & $<5$ \\
& & & $(73.30)$ & $(8.94)$ & $(155.6)$ & \\
\hline
\end{tabular}

( ) : calcd. value 
Table-3 NMR spectral data of 3-(butylhydroxyben= zoyl)acrylic acids in DMSO- $\mathrm{d}_{6} ; \delta(\mathrm{ppm})$ from TMS, J ( $\mathrm{Hz})$. $\mathrm{R}^{\prime}-\mathrm{COCH}=\mathrm{CHCOOH}$

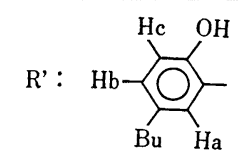

Hc, 7.14 (d)

$\mathrm{Hb}, 7.60$ (dd)

$\mathrm{Ha}, 7.90$ (d)

$\mathrm{J}_{\mathrm{b}, \mathrm{c}}=8.6$

$\mathrm{J}_{\mathrm{a}, \mathrm{b}}=2.0$

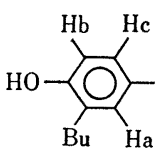

$\mathrm{Hb}, 7.09$ (dd)

Hc, 7.97 (dd)

$\mathrm{Ha}, 7.97$ (d)

$\mathrm{J}_{\mathrm{b}, \mathrm{c}}=9.0$

$\mathrm{J}_{\mathrm{a}, \mathrm{c}}=2.4$

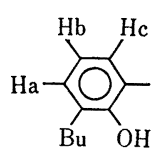

$\mathrm{Hb}, 7.15(\mathrm{dd})$

$\mathrm{Ha}, 7.75$ (dd)

Hc, $8.13(\mathrm{dd})$

$\mathrm{J}_{\mathrm{a}, \mathrm{b}}=7.6$

$\mathrm{J}_{\mathrm{b}, \mathrm{c}}=8.3$

$\mathrm{J}_{\mathrm{a}, \mathrm{c}}=2.0$
ルキル基がブチル基の場合の結果は Table-3 のとおり である。

これらの化合物は 2.1 で述べたときと同様にナトリウ ム塩およびトリエタノールアミン塩とし, 表面張力と抗 菌性とを測定した。3-(2-ヒドロキシー5-アルキルベン ゾイル）アクリル酸トリエタノールアミン塩の定数は次 のとおりである。 $\mathrm{R}=\mathrm{C}_{3} \mathrm{H}_{7}-, \mathrm{mp}\left({ }^{\circ} \mathrm{C}\right) 89 \sim 92, \mathrm{C}(\%)$ 60.04 (60.44), $\mathrm{H}(\%) 7.86$ (7.86), $\mathrm{N}(\%) 3.29$ (3.52); $\mathrm{R}=\mathrm{C}_{7} \mathrm{H}_{15}-\mathrm{mp} 68 \sim 69, \mathrm{C} 63.35$ (63.55), $\mathrm{H} 8.56$ (8.66), N 3.04 (3.08); $\mathrm{R}=\mathrm{C}_{11} \mathrm{H}_{23}-\mathrm{mp} 81 \sim 82, \mathrm{C} 66.10$ (65.98), H 9.17 (9.29), N 2.61 (2.75)。

$2 \cdot 3$ アセチルアミノアルキルベンゾイルアクリ ル 酸 の合成

表題の化合物は Scheme-3 の反応式に従って合成し た。

2・3・1 アセチルアミノアルキルベンゼン $(\mathbf{9})$

先に合成したアルキルベンゼン (1) を常法により濃硫 酸-濃硝酸によりニトロ化し, 減圧蒸留により分留して 次のような沸点を有する $o$-ニトロアルキルベンゼンを 得た。 $\mathrm{R}=\mathrm{C}_{3} \mathrm{H}_{7}-, 129 \sim 131^{\circ} \mathrm{C} / 6 \mathrm{mmHg}(131 \sim 133 / 15)^{7)}$, $n_{\mathrm{D}}^{20} 1.5223 ; \mathrm{R}=\mathrm{C}_{7} \mathrm{H}_{15^{-}}, 148 \sim 149 / 1(182 \sim 184 / 10)^{8)}, n_{\mathrm{D}}^{20}$ $1.5089 ; \mathrm{R}=\mathrm{C}_{11} \mathrm{H}_{23^{-}}, 164 \sim 166 / 1, n_{\mathrm{D}}^{20} 1.5020, \mathrm{~N} \% 4.76$ (4.81)。

これらをスズー塩酸により還元し，oーアミノアルキル ベンゼンを合成し,次のような沸点を有する留分を得た。 $\left.\mathrm{R}=\mathrm{C}_{3} \mathrm{H}_{7}{ }^{-}, \quad 91 \sim 93^{\circ} \mathrm{C} / 1 \mathrm{mmHg}(124 \sim 126 / 15)^{9}\right), n_{\mathrm{D}}^{20} 1.5$ $391 ; \mathrm{R}=\mathrm{C}_{7} \mathrm{H}_{15^{-}}, 143 \sim 144 / 1(175 / 13)^{8)}, n_{\mathrm{D}}^{20} 1.5180 ; \mathrm{R}$ $=\mathrm{C}_{11} \mathrm{H}_{23}{ }^{-}, 161 \sim 163 / 1, n_{\mathrm{D}}^{20} 1.5074, \mathrm{~N} \% 4.70$ (5.36)。 得られた ルベンゼンについては GLCによりその純度を確認し， また必要な官能基については IR スペクトルにより確認 を行った。

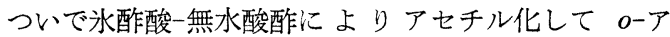
セチルアミノアルキルベンゼン $(\boldsymbol{g})$ を得た。 $\mathrm{mp}\left({ }^{\circ} \mathrm{C}\right)$ は次のとおりである。 $\mathrm{R}=\mathrm{C}_{3} \mathrm{H}_{7}-$ ， 95 96 (94) ${ }^{10)}$; $\mathrm{R}=$
$\mathrm{C}_{7} \mathrm{H}_{15}-78(78)^{8)} ; \mathrm{R}=\mathrm{C}_{11} \mathrm{H}_{23}-83 \sim 84, \mathrm{~N} \% 4.48$ (4.62)。

$2 \cdot 3 \cdot 2$ 3-(4-アセチルアミノ-3-アルキルベンゾイル) アクリル酸 $(10)$

3-(4-アセチルアミノ-3-アルキルベンゾイル) アクリ ル酸の合成例について次に述べる。反応は Pande らの oーアセトトルイジンと無水マレイン酸との反応例を参照 して行った ${ }^{11)}$ 。かくはん棒, 温度計を備えた三つロフラ スコに塩化アルミニウム (無水物) $7.1 \mathrm{~g}(0.054 \mathrm{~mol})$, 二硫化炭素 $30 \mathrm{ml}$ をとり水冷下にかくはんしながら oアセチルアミノオクチルベンゼン $3.7 \mathrm{~g}(0.015 \mathrm{~mol})$ と 無水マレイン酸 $1.84 \mathrm{~g}(0.02 \mathrm{~mol})$ を混合し, ついで二 硫化炭素 $15 \mathrm{ml}$ を加え, $30 \mathrm{~min}$ 水冷下で, 後室温にて $4 \sim 5 \mathrm{~h}$ かくはんして一夜放置後, 内容在水中に注ぎ濃塩 酸 $20 \mathrm{ml}$ 加え，エーテルにて抽出しエーテル溶液を 水洗, 硫酸ナトリウム (無水物) に下乾燥後, エーテル および二硫化炭素を留去し，残分をアセトン：ヘキサン $=2: 5$ の混合溶媒から $\mathrm{mp}$ が一定になるまで再結晶を 繰り返して 3-(4-アセチルアミノ-3-オクチルベンゾイ ル)アクリル酸を $0.73 \mathrm{~g}$, 収率 $13 \%$ こて微黄色結晶と して得た。アルキル基がブチル，ドデシル基の同族体も

Table-4 Characteristics of 3-(4-acetylamino-3alkylbenzoyl)acrylic acids (10)

\begin{tabular}{l|c|c|c|c|c|c}
\hline Alkyl & $\mathrm{mp}\left({ }^{\circ} \mathrm{C}\right)$ & $\mathrm{C} \%$ & $\mathrm{H} \%$ & $\mathrm{~N} \%$ & Yield \% \\
\cline { 1 - 5 } $\mathrm{C}_{3} \mathrm{H}_{7^{-}}$ & $180 \sim 184$ & 65.87 & 6.96 & 4.50 & 17 \\
& & $(65.96)$ & $(7.27)$ & $(4.81)$ & \\
$\mathrm{C}_{7} \mathrm{H}_{15^{-}}$ & \multirow{2}{*}{$142 \sim 144$} & 68.99 & 8.13 & 4.19 & 13 \\
& & $(69.13)$ & $(8.41)$ & $(4.03)$ & 13 \\
$\mathrm{C}_{11} \mathrm{H}_{28^{-}}$ & $144 \sim 146$ & 71.38 & 9.02 & 3.29 & 18 \\
& & $(71.43)$ & $(9.24)$ & $(3.47)$ & \\
\hline
\end{tabular}

( ) : calcd. value

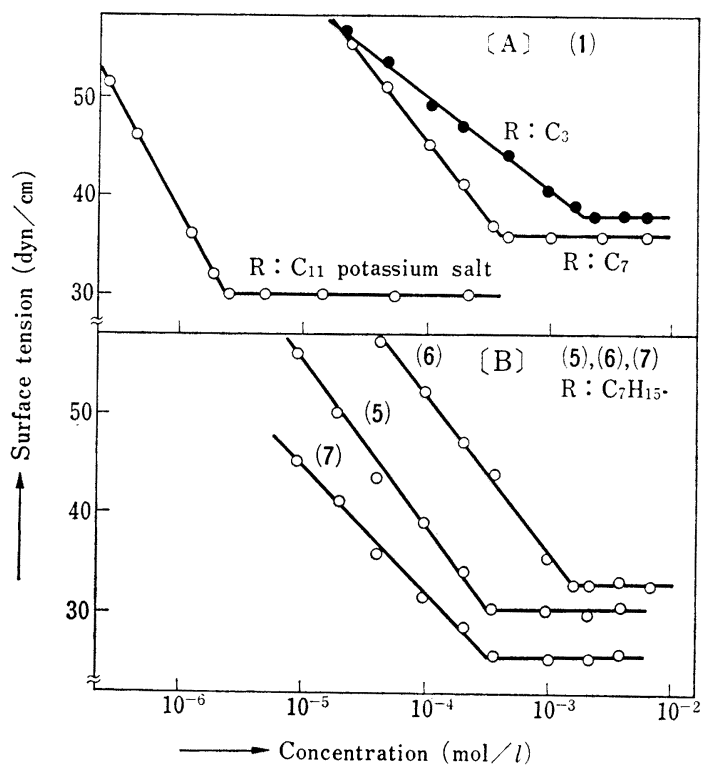

Fig-2. Surface tension-concentration curves of sodium alkylbenzoyl acrylates; [A] : Free $\operatorname{acid}(1),[B]:$ Free acid $(5),(6),(7)$ 
Table-5 Surface tension and $\mathrm{cmc}$ of sodium benzoylacrylates.

\begin{tabular}{|c|c|c|c|c|c|c|c|}
\hline & \multicolumn{5}{|c|}{$\begin{array}{l}\overbrace{5}^{3}{ }_{6}^{2}-\mathrm{CO} \cdot \mathrm{CH}=\mathrm{CHCOONa} \\
\text { Functional groups }\end{array}$} & \multirow{2}{*}{$\begin{array}{c}\mathrm{cmc} \\
(\mathrm{mmol} / \mathrm{l})\end{array}$} & \multirow{2}{*}{$\begin{array}{l}\text { Surface } \\
\text { tension } \\
\text { at } \mathrm{cmc} \\
(\mathrm{dyn} / \mathrm{cm})\end{array}$} \\
\hline & 2 & 3 & 4 & 5 & 6 & & \\
\hline (5) & $-\mathrm{OH}$ & $\mathrm{H}$ & $\mathrm{H}$ & $\mathrm{C}_{3} \mathrm{H}_{7}-$ & $\mathrm{H}$ & 3 & 35 \\
\hline (6) & $\mathrm{H}$ & $\mathrm{C}_{3} \mathrm{H}_{7}^{-}$ & $-\mathrm{OH}$ & $\mathrm{H}$ & $\mathrm{H}$ & - & - \\
\hline (7) & $-\mathrm{OH}$ & $\mathrm{C}_{3} \mathrm{H}_{7}-$ & $\mathrm{H}$ & $\mathrm{H}$ & $\mathrm{H}$ & 10 & 34 \\
\hline (10) & $\mathrm{H}$ & $\mathrm{C}_{8} \mathrm{H}_{7}^{-}$ & $\mathrm{CH}_{3} \mathrm{CONH}-$ & $\mathrm{H}$ & $\mathrm{H}$ & 30 & 36 \\
\hline (10) & $\mathrm{H}$ & $\mathrm{C}_{7} \mathrm{H}_{15-}$ & $\mathrm{CH}_{3} \mathrm{CONH}-$ & $\mathrm{H}$ & $\mathrm{H}$ & 15 & 36 \\
\hline
\end{tabular}

計によって測定した。表面張 力-濃度の関倸を Fig.-2 及び

Table-5 に示した。

\section{5 抗菌性}

抗菌性は寒天希釈法により測 定し, 各化合物の菌体汇対する 最小発育阻止濃度 (MIC) Table-6 及び 7 亿示した。

\section{3 考察}

\section{1 表面張力}

同様に合成した。定数を Table-4 示にす。ベンゼン核 に導入された置換基の位置は NMR スペクトルによっ て確認した。

上に得たアセチルアミノアルキルベンゾイルアクリル 酸をエタノール溶液とし，これを当量の炭酸ナトリウム 水溶液に加え $30 \mathrm{~min}$ 振上うした後溶媒を留去し, 残分 を減王乾燥し，さらにエーテルまたはアセトンにて洗浄 したものを試料とした。

\section{$2 \cdot 4$ 表面張力}

以上合成したアルキルベンゾイルアクリル酸及びその 誘導体塩類の水溶液についてウィルヘルミ一型表面張力
Fig.-2 及び Table-5 に示すようにアルキルベンゾ イルアクリル酸のアルカリ金属塩はアルキル基の炭素数 が $\mathrm{C}_{4}, \mathrm{C}_{8}, \mathrm{C}_{12}$ と增加するにしたがって $\mathrm{cmc}$ が低濃度 側に移動し，かつその表面張力低下能が大きくなる (A)。つぎにヒドロキシル基の影響紊見ると Fig.-2

(B) 沉示すように表面張力低下能法ヒドロキシル基の 位置によって異なった結果を与える。水酸基が不飽和酸 基の o-位をしめるものでは元のヒドロキシル基を含ま ないアルキルベンゾイルアクリル酸上比較して $\mathrm{cmc}$ 㳉 変わらず, 表面張力低下能がいくらか大きくなる。これ に対してヒドロキシル基が不飽和酸基に対し $p$-位にあ

Table- $\hat{\mathbf{0}}$ The MIC of substituted sodium alkylbenzoylacrylates.

$\mathrm{MIC}:(\mu \mathrm{g} / \mathrm{ml})$

\begin{tabular}{|c|c|c|c|c|c|c|c|c|c|c|c|}
\hline \multirow{2}{*}{$\begin{array}{ll}\begin{array}{l}\text { Tested } \\
\text { microorganisms }\end{array} & \begin{array}{l}\text { Free acid } \\
\text { alkyl group }\end{array} \\
\end{array}$} & \multicolumn{3}{|c|}{ (1) } & \multicolumn{2}{|c|}{ (5) } & \multicolumn{2}{|c|}{ (6) } & \multicolumn{2}{|c|}{ (7) } & \multicolumn{2}{|c|}{ (10) } \\
\hline & $\mathrm{C}_{8}$ & $\mathrm{C}_{7}$ & $\mathrm{C}_{11}$ & $\mathrm{C}_{7}$ & $\mathrm{C}_{11}$ & $\mathrm{C}_{7}$ & $\mathrm{C}_{11}$ & $\mathrm{C}_{7}$ & $\mathrm{C}_{11}$ & $\mathrm{C}_{i}$ & $\mathrm{C}_{11}$ \\
\hline Staphylococcus aureus $209 P$ & 12.5 & 6.25 & 25 & $>100$ & 12.5 & - & - & - & - & - & - \\
\hline S. epidermidis 10131 & 6.25 & 3.12 & 50 & $>100$ & 12.5 & - & 一 & - & - & 一 & - \\
\hline Bacillus subtilis PCI-219 & 12.5 & 6.25 & 50 & $>100$ & 12.5 & 100 & $>100$ & 50 & $>100$ & 50 & 50 \\
\hline Sarcina lutea ATCC-1001 & 一 & - & - & - & - & 10 & $>100$ & 50 & 100 & 50 & 10 \\
\hline Escherichia coli NIHJ & $>400$ & $>400$ & $>400$ & $>100$ & $>100$ & $>100$ & $>100$ & $>100$ & $>100$ & 50 & 25 \\
\hline Pseudomonas aeruginosa IFO-3080 & $>400$ & $>400$ & $>400$ & $>100$ & $>100$ & $>100$ & $>100$ & $>100$ & $>100$ & $>100$ & $>100$ \\
\hline Penicillium chrysogenum 49-132 & 400 & $>400$ & $>400$ & $>100$ & $>100$ & 100 & $>100$ & $>100$ & $>100$ & $>100$ & $>100$ \\
\hline Aspergallus niger ATCC & $>400$ & $>400$ & $>400$ & $>100$ & $>100$ & $>100$ & $>100$ & $>100$ & $>100$ & $>100$ & $>100$ \\
\hline
\end{tabular}

Bacilli : Heart infusion agar, $\mathrm{pH} 7.2,24 \mathrm{~h}$

Fungi : Sabouraud's agar, $\mathrm{pH}$ 5.6, $5 \mathrm{~d}$

Table-7 The MIC of substituted alkylbenzoylacrylic acid triethanolamine salts $\mathrm{MIC}:(\mu \mathrm{g} / \mathrm{ml})$

\begin{tabular}{|c|c|c|c|c|c|}
\hline \multirow{2}{*}{$\begin{array}{ll}\text { Tested } & \begin{array}{l}\text { Free acid } \\
\text { microorganisms }\end{array}\end{array}$} & \multicolumn{3}{|c|}{ (1) } & \multicolumn{2}{|c|}{ (5) } \\
\hline & $\mathrm{C}_{3}$ & $\mathrm{C}_{7}$ & $\mathrm{C}_{11}$ & $\mathrm{C}_{7}$ & $\mathrm{C}_{11}$ \\
\hline Staphylococcus aureus $209 P$ & 3.12 & 25 & 6.25 & - & - \\
\hline S. epidermidis 10131 & 1.56 & 12.5 & 3.12 & 一 & - \\
\hline Bacillus subtil is PCI-219 & 3.12 & 25 & 6.25 & $>100$ & $>100$ \\
\hline Sarcina lutea ATCC-1001 & - & 一 & - & 100 & $>100$ \\
\hline Escherichia coli NIHJ & $>100$ & $>100$ & $>100$ & $>100$ & $>100$ \\
\hline Pseudomonas aeruginosa IFO-3080 & $>100$ & $>100$ & $>100$ & $>100$ & $>100$ \\
\hline Penicillium chrysogenum 49-132 & - & - & - & $>100$ & $>100$ \\
\hline Aspergillus niger $A T C C$ & $>100$ & $>100$ & $>100$ & $>100$ & $>100$ \\
\hline
\end{tabular}

Bacilli : Heart infusion agar, $\mathrm{pH} 7.2,24 \mathrm{~h}$

Fungi : Sabouraud's agar, $\mathrm{pH} 5.6,5 \mathrm{~d}$
るものは $\mathrm{cmc}$ は高濃度側に移 行する一方, 表面張力低下作用 はほとんど変化しない。 $p$ 位 にアセチルアミド基をもつもの は元のアルキルベンゾイルアク リル酸上比較して $\mathrm{cmc}$ は高濃 度側に移るぶ $\mathrm{cmc}$ 以上に衫け る表面張力低下能は元のアルキ ルベンゾイルアクリル酸とほぼ 同じである。

\section{2 抗菌性}

Table-6 及び 7 に示すよう に，これらの化合物は一般に 
グラム陰性菌, かびに対しては効果は示さない。ただア セチルアミノ基を導入した場合，そのナトリウム塩にお いて Escherichia coli に対してもいくらか抗菌力を示 した。つぎにナトリウム塩とトリエタノールアミン塩を 比較すると（1）の $\mathrm{R}=\mathrm{C}_{7} \mathrm{H}_{15}$ と（5）の $\mathrm{R}=\mathrm{C}_{11} \mathrm{H}_{23}$ のも のにおいては前者が，また残りのものについては後者が すぐれた抗菌力を持っている。抗菌力が比較的すぐれて いたグラム陽性菌の場合にはベンゼン核に結合するアル キル基がオクチル基の時，一般的に抗菌力が大きいが （5）の 3-(2-ヒドロキシ-5-アルキルベンゾイル) アク リル酸ナトリウム塩に扔いてはアルキル基としてドデシ ル基をもつものがもっとも顕著な抗菌性を示した。ブチ ル基は（1）のものを除いてトリエタノールアミン塩で も，、ずれの菌体化対して $100 \mu \mathrm{g} / \mathrm{ml}$ 以上の $\mathrm{MIC}$ 值で あり良い抗菌力を示さなかった。

またフェノール性ヒドロキシル基の影響をみると 0 位にヒドロキシル基をもつもの (5), (7) では抗菌力は低 下寸る。この結果は Kirchner の (2,4-ジヒドロキシべ ンゾイル）アクリル酸の場合とよく一致し1)，芳香族環 とアクリル酸基とを結ぶカルボニル基が $o$-位のヒドロ キシル基と水素結合を形成し，その結果不活性になると 考えられているが $p$-位にヒドロキシル基をもつ（6）に おいても抗菌力の低下がみられた。つぎにアセチルアミ ノ基をもつものでは元のアルキルベンゾイルアクリル酸 と異なりオクチル基よりもドデシル基を持つものの方が
すぐれた抗菌力を示した。しかしこの場合もヒドロキシ ル基の導入と同様に抗菌力の低下をもたらし，ヒドロキ シル基，アセチルアミノ基の効果は認められなかった。

また以上の結果からアルキルベンゾイルアクリル酸誘 導体の場合, 表面張力低下能と抗菌力の間には直接の相 関関係の存在しないことが明らかである。

（昭和 52 年 5 月 27 日受理）

\section{文献}

1) F.K. Kirchner, J.H. Bailey, C.J. Cavallito, J.Am. Chem. Soc., 71, 1211 (1949)

2) B.J. Cramer, W. Schroeder, W.J. Moran, C.H. Nield, M. Edwards, C.I. Jarowski, B. Puetzer, $J$. Am. Pharm. Assoc., 37, 439 (1948)

3) G. Sandulesco, A. Girard, Bull. Soc. Chim. Fr., (4), 47, 1312 (1930)

4) A.W. Ralston, M.R. McCorkle, S.T. Bauer, $J$. Org. Chem., 5, 645 (1940)

5) N.K. Adam, W,A. Berry, H.A. Turner, Proc. Roy. Soc., (A), 117, 540 (1928)

6）古賀 弥. 日化. 77, 1276 (1956)

7) R.R. Read, D.B. Mullin, J. Am. Chem. Soc., 50, 1763 (1928).; Chem. Abstr., 22, 2370 (1928)

8) I.J. Rinkes, Rec. Trav. Chim., 63, 89 (1928)

9) G. Vavon, A. Guedon, Bull. Soc. Chim. Fr., (4), 47, 901 (1930); Chem. Abstr., 25, 1808 (1931)

10) W.P. Neumann, Angew. Chem., 70, 401 (1958)

11) C.S. Pande, S.K. Gandhi, Bull. Chem. Soc. Jpn., 40, 1987 (1967)

\section{訂 正}

油化学 26，8月号 (1977) に下記のような誤りがありましたので訂正いたします。

\begin{tabular}{|c|c|c|c|}
\hline ページ & 行 & 詥 & 正 \\
\hline 458 & 英文 4 & Ana their building performances detergency & And their detergency building performances \\
\hline$"$ & " 5 & in a sysem & in a system \\
\hline 461 & 右下 4 & ナトリウム（無水物） & 硫酸ナトリウム（無水物） \\
\hline 462 & 右 10,22 & 自由度 $\varphi$ & 自由度 $\phi$ \\
\hline 463 & 上の表 & $(\text { VIII })_{n=1}-\mathrm{Na},(\mathrm{VIII})_{n=1}-\mathrm{Na}$ & $(\text { VIII })_{n=1}-\mathrm{Na},(\text { VIII })_{n=2}-\mathrm{Na}$ \\
\hline 470 & 右式最下段 & $\mathrm{C}_{n} \mathrm{H}_{2 n}-\mathrm{C}-\mathrm{CH}_{2}$ & $\mathrm{C}_{n} \mathrm{H}_{2 n}-\mathrm{C}-\mathrm{CH}_{2}$ \\
\hline & $\Gamma$ & $\mathrm{C}_{n+2} \mathrm{H}_{2 n+5} \mathrm{OH} \quad$ （II) & $\mathrm{C}_{n+2} \mathrm{H}_{2 n+5} \mathrm{OH} \mathrm{OH} \quad$ (II) \\
\hline 472 & Fig. 4 & Benzylhxadecyl & Benzylhexadecyl \\
\hline 499 & 左 2 & OH が院イオンと & OH が陽イオンと \\
\hline
\end{tabular}

